\title{
António Egas Moniz (1874-1955): Lobotomy pioneer and Nobel laureate
}

Siang Yong $\operatorname{Tan}^{1}$, MD, JD, Angela Yip ${ }^{2}$, MS

1 $t$ the turn of the 20th century, a bolder generation of psychiatrists began using psychoanalysis to treat psychosis. They also began experimenting with ever more invasive techniques, such as the use of insulin and camphor to induce convulsions. This was soon followed by electric shock therapy, which became the treatment of choice in psychotic depression. An area that gained popularity - and notoriety - was psychosurgery. The pioneer in this particular field, Portuguese doctor António Egas Moniz, introduced the infamous frontal lobotomy for refractory cases of psychosis, winning for himself the Nobel Prize for a "technique that just possibly came too soon for the technology and medical philosophy of its own epoch."

\section{EARLY CAREER IN MEDICINE} Born on 19 November 1874, in the northern coastal village of Avanca, Portugal, on an estate that had belonged to his aristocratic family for 500 years, Moniz was baptised António Caetano de Abreu Freire. His godfather later named him Egas Moniz after a famous nobleman who was the tutor to Portugal's first king. Moniz attended medical school at the University of Coimbra, Portugal, and later travelled to France, where he received training in neurology and psychiatry from renowned French doctors like Jean-Athanase Sicard, Joseph Babinski,

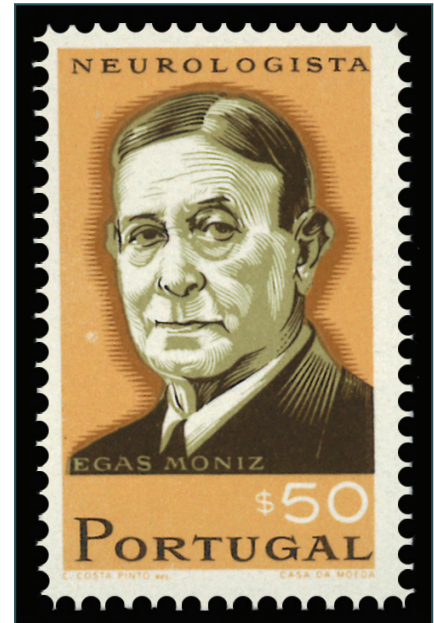
Pierre Marie and Joseph Jules Dejerine. In 1911, Moniz returned to Portugal to head the new specialty of neurology at the University of Lisbon, Portugal, and remained there until his retirement in 1944.

IMAGING THE BRAIN Having devoted most of his early years to politics, Moniz was a late starter in medicine. It was only upon retiring from politics in 1926 at the age of 51 that he was able to concentrate on his research in neurology. Believing that visualisation of the blood vessels of the brain by radiographic means could lead to more precise localisation of brain tumours, Moniz experimented with the injection of radiopaque dyes into brain arteries, which allowed them to be photographed and traced for anomalies. His initial attempts at the procedure used strontium and lithium bromide in three patients with a suspected brain tumour, epilepsy and parkinsonism. Unfortunately, the experiment failed and one patient died. Undeterred, Moniz next injected a 25\% sodium iodide solution into another three patients. This proved to be a safer approach, creating a clear angiogram - the first of its kind. In July 1927, Moniz presented his findings at the Neurological Society in Paris, and then at the French Academy of Medicine. Other scientists had previously attempted to visualise peripheral structures using radiopaque substances, but Moniz was the first to successfully apply it to the human brain. His work in this area subsequently led to the use of angiography in the detection of internal carotid artery occlusion, which was until then a frequently missed diagnosis. History credits a young neurosurgeon, Almeida Lima, for ably assisting in the delicate angiographic procedure, as Moniz himself suffered from deforming gouty arthritis of the hands. Although Moniz was nominated twice for the Nobel Prize for his groundbreaking research in cerebral imaging, it was his work in psychosurgery, an entirely different area, which eventually won him the Prize.

ORIGINS OF LOBOTOMY Moniz's decision to perform experimental psychosurgery is attributed by many to a paper presented by two Yale physiologists, Carlyle Jacobsen and John Fulton, at the Second International Congress of Neurology in London in 1935. The two researchers described how a chimpanzee with both frontal lobes removed became more cooperative and willing to accomplish tasks, while displaying no frustration. Prior to the surgery, one of the chimpanzees, Becky, had reacted to performing specific tasks in a highly volatile way, refusing to enter the chamber or becoming enraged following an error. Richard Brickner, a neurologist, also influenced Moniz with his report of a stockbroker with a large frontal meningioma. After sections of the stockbroker's frontal lobe were removed, the man was left with an intact intellect, but showed a noticeable change in personality. Initially "shy and introverted", the stockbroker became "vivacious and boastful" following the surgery.

Moniz's hypothesis was that, in mentally ill patients, the presence of abnormal neural connections originate from the frontal lobes. Working at the University of Lisbon, Moniz

${ }^{1}$ Emeritus Professor of Medicine, University of Hawaii, ${ }^{2}$ Research carried out during 4th year medical student elective, John A Burns School of Medicine, University of Hawaii, Honolulu, USA

Correspondence: Prof Tan Siang Yong, 2230 Liliha Street, Suite 104, Honolulu, HI 96817, USA. siang@hawaii.edu 
believed that certain obsessive and melancholic persons could be helped if their frontal lobes were excised. In order to accomplish the leucotomy, Moniz again worked with Lima to develop a needle-like instrument with a retractable wire loop. The instrument, named a leucotome, allowed the wire to travel through the posterior aspect of the frontal lobe, cutting through the white matter fibres of the brain. In earlier procedures, Moniz used absolute alcohol to destroy the frontal lobe. Moniz's first psychosurgery, performed on 12 November 1935, was described by the Nobel Committee as one of the most important discoveries ever made in psychiatric medicine. In that case, the patient was a 63-year-old woman suffering from depression, anxiety, paranoia, hallucinations and insomnia. Barahona Fernandes, a psychiatrist, evaluated the patient two months following the alcohol injection to the frontal lobes, remarking that "the patient's anxiety and restlessness had declined rapidly with a concomitant marked attenuation of paranoid features". For his contribution to psychosurgery and psychiatry, Moniz received the 1949 Nobel Prize in Physiology or Medicine.

Following Moniz's initial leucotomy procedures, other physicians, including American neurologists Walter Freeman and James Winston Watts, enthusiastically adopted and refined the procedure. They brought the technique to the United States, and renamed the surgery a lobotomy.

However, a cynical public soon began questioning whether the effects of a lobotomy were in fact worse than the disease it purported to cure. Unarguably more manageable post lobotomy, lobotomised patients were also left with irreversible changes in their persona, and were described as mental invalids and drooling zombies. Moniz himself came under attack for understating the complications, inadequate documentation and poor patient follow-up. Incredibly, despite such jarring criticisms, lobotomies became a mainstay of surgical psychiatric treatment. Until the advent of antipsychotic drugs in the 1960s when lobotomies rapidly fell into disfavour and faded into oblivion, some 5,000 lobotomies were performed in the United States alone.

POLITICIAN AND AUTHOR Moniz was always interested in politics. An activist, he was jailed on two separate occasions as a student, and for a third time during his tenure as the Dean of the Medical School at the University of Lisbon, for preventing the police from entering and settling an on-campus student-run protest. Moniz held various political positions; his talents allowed him to maintain political leverage despite frequent leadership changes in the Portuguese government. However, in 1926, Moniz left politics entirely when António de Oliveira Salazar gained power following a military coup d'etat, and Portugal abandoned the liberal democracy that had allowed Moniz to flourish.
A prolific author who wrote and published on a wide variety of subjects, Moniz's work included Portuguese literature, sexology and two autobiographies. After graduating from medical school, he gained immediate notoriety by publishing A Vida Sexual, a series of controversial and scandalous books. His assorted writings also include a biography of Padre Faria, a monk and hypnotist from the former Portuguese colony of Goa on the west coast of India; a biography of a Portuguese physician Pedro Hispano Portucalense who became Pope John XXI in the 13th century; and a book on the history of playing cards, reflecting Moniz's interest in gambling. In medical writing, Moniz was even more prolific, producing 61 papers and a book on angiography between 1927 and 1931. By 1934, Moniz's publications on angiography alone totalled 112 articles and 2 books. As professor of neurology at the University of Lisbon, he also wrote on neurological war injuries, Parkinson's disease and clinical neurology.

BRUSH WITH DEATH Moniz has been described as a "dedicated, compassionate physician and brilliant teacher who drew people from everywhere to his conferences and lectures". He was regarded as a gentleman of society who took pleasure in entertaining the children of his friends, in part perhaps because he had no children of his own. He enjoyed being seen as the suave diplomat who took pride in entertaining his guests and overseeing the menu, choice of wines, and even the uniforms of the servants. He owned an extensive library and collection of antiques, and was steeped in art, history and literature, regularly lecturing on diverse topics in his capacity as the president of the Sciences Academy of Lisbon. In 1939, Moniz survived several near-fatal gunshot wounds fired by a schizophrenic patient. Moniz lived on till the age of 81, dying from an internal haemorrhage on 13 December 1955.

\section{BIBLIOGRAPHY}

- The Nobel Foundation. Egas Moniz - Biographical. In: The Official Web Site of the Nobel Prize [online]. Available at: http://nobelprize. org/nobel_prizes/medicine/laureates/1949/moniz-bio.html. Accessed March 31, 2014.

- Haas LF. Neurological Stamp. Egas Moniz (1874-1955). J Neurol Neurosurg Psychiatry 2003; 74:653.

- Lowis GW, Minagar A. The neglected research of Egas Moniz of internal carotid artery (ICA) occlusion. J Hist Neurosci 2003; 12:286-91.

- McGrew RE, Margaret P. Encyclopedia of Medical History. New York: McGraw-Hill, 1985.

- Raju TN. The Nobel chronicles. 1949: Walter Rudolf Hess (1881-1973); and Antonio Egas Moniz (1874-1955). Lancet 1999; 353:1281.

- Sachdev P. Egas Moniz: a commemoration. Aust N Z J Psychiatry 1999; 33:463-6.

- Tierney AJ. Egas Moniz and the origins of psychosurgery: a review commemorating the 50th anniversary of Moniz's Nobel Prize. J Hist Neurosci 2000; 9:22-36.

- Tondreau RL. The retrospectoscope. Egas Moniz 1874-1955. Radiographics 1985; 5:994-7. 